\title{
ANALISIS EFEKTIVITAS PENETRALAN AIR ASAM TAMBANG MENGGUNAKAN KAPUR TOHOR DAN SODA ASH DARI KOLAM PENGENDAPAN LUMPUR PIT TAMBANG BATUBARA DALAM SKALA LABORATORIUM
}

\section{ANALYSIS OF THE EFFECTIVENESS OF MINING ACID WATER NEUTRALIZATION USING CALCIUM OXIDE AND SODA ASH FROM COAL MINE PIT IN LABORATORY SCALE}

\author{
Lina Rianti $^{1)}$, Maryana ${ }^{2)}$, Aprianti $^{3)}$ \\ ${ }^{1,2,3)}$ Program Studi Teknik Pertambangan Batubara Politeknik Akamigas Palembang, 30257, Indonesia \\ Corresponding Author E-mail: linarianti@pap.ac.id
}

\begin{abstract}
Previous research was carried out by Fitri in 2019 regarding neutralization using calcium oxide and soda ash, but the number of samples used had not met the standard number of samples statistically, namely \pm 30 samples. So in this research there will be more emphasis on the comparison of the neutralization of acid mine drainage using calcium oxide and soda ash in a coal mine with a sample size of \pm 30 samples. The purpose of this study was to determine the effectiveness of increasing the $\mathrm{pH}$ of acid mining water using calcium oxide or soda ash. Sampling at a coal mining company in Lahat. Testing and sample analysis were carried out at the Akamigas Palembang Polytechnic Laboratory. The initial pH obtained in the field was 6.3 which met environmental quality standards. This research is more focused on the comparison of the increase in $\mathrm{pH}$ using soda ash and calcium oxide. From the laboratory test results, it was found that soda ash at a dose of 0.1 gram had an average $\mathrm{pH}$ increase of 1.673 ; at a dose of 0.2 grams the increase in $\mathrm{pH}$ is an average of 1.8; and at a dose of 0.3 gram an average $\mathrm{pH}$ increase of 1.9. The test results in the laboratory were obtained for calcium oxide at a dose of 0.1 gram with an average $\mathrm{pH}$ increase of 1.2 ; at a dose of 0.2 grams of increase in $\mathrm{pH}$ an average of 1.3; and at a dose of 0.3 gram an average $\mathrm{pH}$ increase of 1.4. Based on the test results, it was found that the effectiveness level of increasing $\mathrm{pH}$ using soda ash was higher than calcium oxide. To improve the results and development of this research, it is requested that in further research to be investigated more deeply regarding other indicators, not only an increase in $\mathrm{pH}$, for example, economically and other technically.

Keywords: Acid Mine Drainage, Soda Ash, Calcium Oxide.
\end{abstract}

\begin{abstract}
Abstrak: Penelitian sebelumnya telah dilakukan oleh Fitri tahun 2019 mengenai penetralan menggunakan kapor tahor dan soda ash, namun jumlah sampel yang digunakan belum memenuhi jumlah standar sampel secara statistika yaitu \pm 30 sampel. Maka pada penelitian kali ini akan lebih ditekankan pada perbandingan penetralan air asam tambang menggunakan kapur tohor dan soda ash pada tambang batubara dengan jumlah sampel \pm 30 sampel. Tujuan penelitian ini adalah untuk mengetahui keefektifan kenaikan pH air asam tambang menggunakan kapur tohor atau soda ash. Pengambilan sampel di salah satu Perusahaan Tambang Batubara di Lahat. Pengujian dan analisis sampel dilakukan di Laboratorium Politeknik Akamigas Palembang. pH awal yang didapatkan di lapangan sebesar 6,3 sudah memenuhi baku mutu lingkungan. Pada penelitian ini lebih difokuskan pada perbandingan kenaikan pH dengan menggunakan soda ash dan kapur tohor. Dari hasil pengujian di laboratorium didapatkan untuk soda ash pada dosis 0,1 gram kenaikan pH rata-rata sebesar 1,673; pada dosis 0,2 gram kenaikan pH rata-rata sebesar 1,8; dan pada dosis 0,3 gram kenaikan pH rata-rata sebesar 1,9. Hasil pengujian di laboratorium didapatkan untuk kapur tohor pada dosis 0,1 gram kenaikan pH rata-rata sebesar 1,2; pada dosis 0,2 gram kenaikan pH rata-rata 1,3; dan pada dosis 0,3 gram kenaikan pH rata-rata sebesar 1,4. Berdasarkan hasil pengujian tersebut didapatkan tingkat keefektifan kenaikan pH menggunakan soda ash lebih tinggi daripada kapur tohor. Untuk memperbaiki hasil dan pengembangan penelitian ini maka disarankan dalam penelitian selanjutnya dapat diteliti lebih dalam mengenai indikator lain bukan hanya tingkat kenaikan pH misalnya secara ekonomis dan teknis yang lainnya.
\end{abstract}

Kata kunci : Air Asam Tambang, Soda Ash, Kapur Tohor

\section{PENDAHULUAN}

\subsection{Latar Belakang}

Batubara diartikan sebagai batuan sedimen yang berasal dari material organik (organic clastic sedimentary rock), dapat dibakar dan memiliki kandungan utama berupa
C, H, O (Sukandarrumidi, 2004). Air asam tambang merupakan istilah umum yang digunakan untuk menjelaskan lindian (leachate), rembesan (seepage), atau aliran (drainage) yang telah dipengaruhi oksidasi alamiah mineral sulfida pada batuan yang 
terpaparkan (exposed). Air asam tambang umumnya berwarna coklat kemerahan dan terdapat endapan material dalam air yang berwarna kuning kecokalatan, tetapi hal ini tidak selalu terjadi, karena air asam tambang ada juga yang berwarna jernih. Apabila secara visual air tersebut tidak dapat diketahui, maka dilakukan pengukuran menggunakan $\mathrm{pH}$ meter. Air dikatakan asam apabila memiliki nilai pH di bawah 5 (Linggasari, 2018).

Kapur tohor atau dikenal pula dengan nama kimia kalsium oksida $(\mathrm{CaO})$, adalah hasil pembakaran kapur mentah (kalsium karbonat atau $\mathrm{CaCO}_{3}$ ) pada suhu kurang lebih $90^{\circ} \mathrm{C}$. Jika disiram dengan air, maka kapur tohor akan menghasilkan panas dan berubah menjadi kapur padam (kalsium hidroksida, $\mathrm{CaOH})$. Istilah yang luas digunakan "kapur" berkonotasi bahan anorganik yang mengandung kalsium, yang meliputi karbonat, oksida dan hidroksida kalsium, silikon, magnesium, aluminium, dan besi mendominasi, seperti batugamping (Linggasari, 2018).

Natrium karbonat juga dikenal sebagai soda cuci dan soda abu $\left(\mathrm{Na}_{2} \mathrm{CO}_{3}\right)$ adalah garam natrium dari asam karbonat yang mudah larut dalam air. Natrium karbonat murni berwarna putih, bubuk tanpa warna yang menyerap embun dari udara, punya rasa alkalin atau pahit, dan membentuk larutan alkali yang kuat. Natrium karbonat juga merupakan salah satu karbonat yang paling penting dari semua alkali karbonat. Natrium karbonat ditemukan dalam bentuk anhidrat (soda ash), monohidrat $\mathrm{Na}_{2} \mathrm{CO}_{3} \cdot \mathrm{H}_{2} \mathrm{O}$ dan paling banyak ditemukan dalam bentuk dekahidrat $\mathrm{Na}_{2} \mathrm{CO}_{3} \cdot 10 \mathrm{H}_{2} \mathrm{O}$ (washing soda). Natrium karbonat dekahidrat merupakan kristal transparan yang jika dipanaskan akan membentuk deposit bubuk dari natrium karbonat monohidrat (Vernandes, 2017).

Dari penelitian Metboki tahun 2018 penetralan air asam tambang dilakukan menggunakan kapor tahor, dan penelitian Linggasari tahun 2018 menggunakan soda ash. Penelitian sebelumnya juga telah dilakukan oleh Fitri tahun 2019 penetralan menggunakan kapor tahor dan soda ash, namun jumlah sampel yang digunakan belum memenuhi jumlah standar sampel secara statistika, yaitu \pm 30 sampel. Maka pada penelitian kali ini akan lebih ditekankan pada perbandingan penetralan air asam tambang menggunakan kapur tohor dan soda ash pada tambang batubara dengan jumlah sampel \pm 30 sampel.

\subsection{Batasan Masalah} meliputi :

Batasan masalah dalam penelitian ini

1. Pengujian efektifitas kenaikan $\mathrm{pH}$ air asam tambang menggunakan soda ash dan kapur tohor.

2. Lokasi pengambilan sampel air di Perusahaan Tambang Batubara di Lahat.

3. Pengujian dilakukan di Laboratorium Politeknik Akamigas Palembang.

\subsection{Tujuan Penelitian}

Tujuan penelitian ini adalah untuk mengetahui keefektifan kenaikan $\mathrm{pH}$ air asam tambang antara menggunakan kapur tohor dan soda ash.

\subsection{Manfaat Penelitian}

Manfaat penelitian ini adalah dapat menentukan bahan penetral yang lebih efektif dalam meningkatkan $\mathrm{pH}$ air asam tambang.

\section{TEORI DASAR}

\subsection{Batubara}

Batubara diartikan sebagai batuan sedimen yang berasal dari material organik (organic clastic sedimentary rock), dapat dibakar dan memiliki kandungan utama berupa C, H, O (Sukandarrumidi, 2004). Batubara adalah bahan bakar padat yang mengandung abu, oleh sebab itu dalam pemanfaatanya diperlukan biaya yang cukup tinggi dalam proses penangananya (coal handling).

Sulfur adalah salah satu komponen dalam batubara, yang terdapat sebagai sulfur organik maupun anorganik. Umumnya komponen sulfur dalam batubara terdapat sebagai syngenetik yang erat hubunganya dengan proses fisika dan kimia selama proses penggambutan dan dapat juga sebagai sulfur epigenetik yang dapat diamati sebagai pirit pengisi cleat pada batubara, juga sebagai epigenetik yang dapat diamati sebagai pirit pengisi cleat pada batubara akibat proses 
presipitasi kimia pada akhir proses pembatubaraan.

\subsection{Definisi Asam Tambang}

Air asam tambang merupakan istilah umum yang digunakan untuk menjelaskan lindian (leachate), rembesan (seepage), atau aliran (drainage) yang telah dipengaruhi oksidasi alamiah mineral sulfida pada batuan yang terpaparkan (exposed). Air asam tambang umumnya berwarna coklat kemerahan dan terdapat endapan material dalam air yang berwarna kuning kecokalatan, tetapi hal ini tidak selalu terjadi, karena air asam tambang ada juga yang berwarna jernih. Apabila secara visual air tersebut tidak dapat diketahui, maka dilakukan pengukuran menggunakan $\mathrm{pH}$ meter. Air dikatakan asam apabila memiliki nilai $\mathrm{pH}$ dibawah 5 (Linggasari, 2018).

\subsection{Sumber Air Asam Tambang}

Air asam tambang atau biasa disebut juga dengan acid mine drainage (AMD), atau bisa juga disebut sebagai acid rock drainage $(A R D)$ terjadi sebagai akibat proses fisik dan kimia yang cukup kompleks yang melibatkan beberapa faktor dalam kegiatan penambangan. Kegiatan penambangan ini dapat berupa tambang terbuka maupun tambang bawah tanah. Umumnya keadaan ini terjadi karena sulfur yang terdapat di dalam batuan teroksidasi secara alamiah (pada proses pembukaan tambang). Selanjutnya dengan kondisi kelembaban lingkungan yang cukup tinggi akan menyebabkan oksida sulfur tersebut berubah menjadi asam (Linggasari, 2018).

Menurut Suparno (2011), sumbersumber air asam tambang ini antara lain berasal dari kegiatan-kegiatan sebagai berikut : a. Pengupasan lapisan tanah atau batuan penutup

Lapisan batuan akan terbuka sebagai akibat dari terkupasnya lapisan penutup, sehingga unsur sulfur yang terdapat dalam batuan sulfida akan mudah teroksidasi dan bila bereaksi dengan air dan oksigen akan membentuk air asam tambang.

b. Air dari Unit Pengelolaan Batuan Buangan (waste rock)
Material yang banyak terdapat pada limbah kegiatan penambangan adalah batuan buangan (waste rock). Jumlah batuan buangan ini akan semakin meningkat dengan bertambahnya kegiatan penambangan. Sebagai akibatnya, batuan buangan yang banyak mengandung sulfur akan berhubungan langsung dengan udara terbuka membentuk senyawa sulfur oksida selanjutnya dengan adanya air akan membentuk air asam tambang.

c. Air dari lokasi penimbunan batuan

Timbunan batuan yang berasal dari batuan sulfida dapat menghasilkan air asam tambang karena adanya kontak langsung dengan udara yang selanjutnya terjadi pelarutan akibat adanya air.

d. Air dari Unit Pengolahan Limbah Tailing

Kandungan unsur sulfur di dalam tailing diketahui mempunyai potensi dalam membentuk air asam tambang, $\mathrm{pH}$ dalam tailing pond ini biasanya cukup tinggi karena adanya penambahan hydrated lime untuk menetralkan air yang bersifat asam yang dibuang kedalamnya. Air yang masuk ke dalam tailing pond yang bersifat asam tersebut diperkirakan akan menyebabkan limbah asam bila merembes keluar dari tailing pond.

\subsection{Pengolahan Air Asam Tambang}

Cara pengolahan air asam tambang dibedakan menjadi dua metode, yaitu metode aktif dan pasif. Pengolahan dengan metode aktif adalah pengolahan dengan menambahkan bahan kimia pembentuk basa yang bertujuan untuk menetralkan $\mathrm{pH}$ air, sedangkan pengolahan dengan metode pasif cenderung mengandalkan kemampuan fisik alam atau dapat disebut sebagai metode yang dilakukan dengan menggunakan bahan alami (Taylor, 2005).

Sistem pengolahan aktif merupakan metode yang dilakukan melalui penambahan bahan kimia dalam proses netralisasi air asam tambang. Sistem ini membutuhkan bantuan manusia dan bantuan instrumen pendukung lainnya dalam pengoperasian. Kelebihan sistem ini yakni memiliki efisiensi pengolahan yang cenderung lebih tinggi dan lebih mudah dalam pengontrolan pengoperasiannya. Namun sistem ini membutuhkan biaya konstruksi, 
operasi, dan perawatan yang relatif cukup besar (Taylor, 2005).

Pengolahan air asam tambang secara aktif berdasarkan teknik pencampurannya terbagi menjadi dua macam, yaitu sistem batch dan sistem continue. Sistem batch adalah sistem pengolahan air asam tambang yang dilakukan untuk debit air yang kecil, sedangkan sistem continue digunakan untuk debit air yang besar dengan penambahan bahan kimia yang dilakukan secara continue (Linggasari, 2018).

Berikut beberapa jenis bahan kimia yang digunakan dalam pengolahan metode aktif (Linggasari, 2018):

\section{1) Batukapur (limestone)}

Penggunaan batukapur ini merupakan penanganan yang memiliki biaya termurah dan merupakan bahan yang paling aman dan termudah dari semua bahan-bahan kimia.

2) Kapur terhidrasi/kapur padam (hydrated lime)

Kapur padam sangat efektif dari segi biaya untuk volume air yang cukup besar dan keadaan asam yang tinggi.

\section{3) Caustic soda (sodium hydroxyide)}

Caustic soda merupakan bahan kimia yang biasa digunakan pada kondisi aliran air yang rendah. Caustic soda dapat menaikkan $\mathrm{pH}$ air asam tambang dengan sangat cepat, sangat mudah larut dan biasanya digunakan untuk air asam tambang dengan kandungan mangan yang tinggi. Penggunaannya sangat sederhana, yaitu dengan mencampurkan caustic soda kedalam air asam tambang. Kekurangan dari caustic soda ini sendiri adalah biayanya yang cukup tinggi namun cautic soda padat lebih murah dibandingkan dengan caustic soda cair.

4) Soda $a s h$

Soda ash atau sodium carbonate biasanya digunakan dalam debit kecil dengan kandungan besi yang rendah. Pemilihan soda ash untuk penanganan air asam biasanya berdasar pemakaian sebuah kotak atau tong dengan air masuk dan buangan.

\section{6) Anhydrous Ammonia}

Anhydrous ammonia digunakan dalam beberapa cara untuk menetralkan keasaman dan juga untuk mengendapkan logam-logam di dalam air asam tambang. Ammonia diinjeksikan ke dalam kolam air air asam tambang, injeksi ammonia sebaiknya dekat dengan dasar kolam karena ammonia lebih ringan dibandingkan dari pada air sehingga amonia sangat cepat naik ke permukaan saat belum bereaksi dengan air asam tambang sepenuhnya.

\subsection{Metode Sampling}

Pengambilan contoh air (water sampling) merupakan salah satu bagian yang tidak terpisahkan dari sistem pengukuran kualitas air, yaitu untuk mendapatkan data kualitas air yang akurat dan valid.

Untuk mendapatkan data hasil pengukuran yang valid (representatif) (Laboratorium Lingkungan TL-3103. ITB), diperlukan :

a. Contoh air yang representatif

b. Metode analisis dengan tingkat akurasi dan presisi yang dapat diterima

c. Peralatan dan instrumentasi yang terkalibrasi

d. Sumber daya manusia (analis atau laboran) yang dibekali dengan pengetahuan dan keterampilan yang memadai.

Pengertian contoh air yang representatif adalah contoh air yang komposisinya sama dengan komposisi badan air (sungai, waduk, laut, sumur, dan sebagainya) yang akan diteliti kualitasnya. Jika contoh air yang akan dianalisis adalah contoh air yang karakteristik asalnya (badan airnya), maka ketika dianalisis di laboratorium, data yang diperoleh adalah data yang tidak sama dengan kualitas badan air tersebut, sehingga data yang diperoleh tidak representatif, sehingga akan menimbulkan kesalahan dalam membuat kesimpulan tentang kualitas badan air tersebut, yang selanjutnya akan menimbulkan kesalahan yang lebih jauh, yaitu kesalahan dalam mengambil kebijakan yang akan diterapkan dalam rangka pengelolaan kualitas air tersebut.

Maksud dan tujuan pengambilan contoh air adalah mengumpulkan volume air dari badan air yang akan diteliti kualitasnya dengan 
volume sekecil mungkin tetapi karakteristik dan komposisinya masih sama dengan karakteristik badan air tersebut.

Untuk mendapatkan contoh air yang representatif diperlukan beberapa persyaratan (Laboratorium Lingkungan TL-3103. ITB) diantaranya:

a. Pemilihan lokasi yang tepat,

b. Teknik pengambilan contoh, dan

c. Metode pengawetan contoh

\subsubsection{Pemilihan Lokasi Pengambilan Contoh Air}

Pemilihan lokasi pengambilan contoh air merupakan salah satu langkah penting dalam prosedur pengambilan contoh air, lokasi pengambilan contoh dipilih agar contoh air yang diambil benar-benar mewakili badan air tersebut, agar diperoleh hasil pengukuran yang representatif. Pemilihan lokasi harus mempertimbangkan tujuan dari pengukuran, pemantauan dan pengetahuan tentang kondisi dan geografi dari badan air yang diteliti.

Lokasi pengambilan contoh air berasal dari aktivitas pertambangan batubara. Air tersebut biasanya terkumpul dalam suatu sump yang kondisinya seperti danau atau waduk. Untuk itu, berikut akan diberikan pedoman umum dalam pemilihan lokasi pengambilan contoh air di danau atau waduk.

Kualitas air di danau atau waduk sangat dipengaruhi oleh kondisi air yang masuk, lebar dan kedalaman dari danau, dan untuk setiap tempat mempunyai kualitas air yang berbeda-beda. Jika tujuan pengambilan contoh untuk mengetahui kualitas air yang keluar dari danau, maka titik pengambilan contoh dipilih dari keluaran danau atau waduk tersebut. Tetapi jika ingin mengetahui kualitas air di badan air tersebut dapat dilakukan transect sampling, yaitu pengambilan contoh pada berbagai tempat dan kedalaman dari danau tersebut.

Menurut SNI, pengambilan contoh air di danau adalah sebagai berikut :

a. Untuk danau dengan kedalaman $<10$ meter, contoh diambil di 2 (dua) titik, yaitu di permukaan dan di dasar danau. b. Untuk kedalaman 10-30 meter, contoh diambil di 3 (tiga), yaitu di permukaan, di lapisan tengah dan di dasar sungai.

c. Untuk kedalaman 30-100 meter, contoh diambil di 4 (empat) titik, yaitu di permukaan, di tengah bagian atas, di tengah bagian bawah, dan di bagian dasar.

\subsubsection{Teknik Pengambilan Contoh Air}

Dalam pengambilan contoh air dikenal dengan istilah grab sample (contoh air sesaat) dan composite sample (contoh air campuran) (Laboratorium Lingkungan TL-3103. ITB).

a. Contoh air sesaat (grab sample)

Istilah contoh air sesaat adalah contoh air yang diambil pada satu kali pengambilan dari satu lokasi. Dengan demikian data hasil pengukuran hanya mewakili kualitas air pada saat dilakukan pengambilan dan pada titik pengambilan, oleh sebab itu pengambilan contoh air sesaat hanya dilakukan untuk badan air yang kualitasnya relatif stabil. Contohnya air sumur dalam. Pengambilan contoh sesaat juga digunakan untuk studi pendahuluan, yaitu untuk mengetahui kualitas badan air secara umum.

b. Contoh air komposit (composite sample)

Contoh air komposit adalah contoh air campuran yang diambil dari satu lokasi, dengan beberapa kali periode pengambilan dalam rentang waktu tertentu. Kemudian contoh-contoh air tersebut digabungkan dicampurkan menjadi satu contoh. Dengan demikian data hasil pengukuran contoh air komposit merupakan data kualitas air rata-rata selama selang waktu tertentu.

Pengambilan contoh air secara komposit dapat dilakukan untuk badan air yang kualitas airnya berubah terhadap perubahan tempat. Maka pengambilan contoh harus dilakukan pada beberapa lokasi, kemudian digabungkan. Contoh air sungai, maka harus dilakukan pengambilan contoh pada beberapa lokasi, sepanjang lebar sungai tersebut, kemudian contoh-contoh air tersebut digabungkan menjadi satu contoh. Contoh air yang demikian juga sering dinamakan integrated sample. 


\subsubsection{Pengawetan Contoh Air}

Pengawetan contoh air adalah perlakuan-perlakuan yang diterapkan terhadap contoh air dengan tujuan agar kualitas air tidak berubah selama perjalanan dari lokasi sampling ke laboratorium, selama penyimpanan di laboratorium, dan menunggu untuk dianalisis (Laboratorium Lingkungan TL-3103. ITB). Metode pengawetan untuk setiap parameter berbeda-beda tergantung pada karakteristik parameter yang ada di dalam air, dan setiap pengawetan mempunyai batas waktu pengawetan karena proses pengawetan bertujuan agar senyawa kimia yang akan diuji tidak berubah selama penyimpanan.

Menurut Laboratorium Lingkungan TL-3103, ITB; pengawetan contoh air dikelompokkan dalam:

a. Pengawetan dengan cara pendinginan $4^{\circ} \mathrm{C}$ (contohnya untuk parameter BOD, asidialkalinitas, warna, konduktifitas, dll.)

b. Pengawetan dengan penambahan $\mathrm{H}_{2} \mathrm{SO}_{4}$ pekat sampai $\mathrm{pH}<2$ dan pendinginan $4^{\circ} \mathrm{C}$. (untuk 1liter contoh air ditambah $\pm 1 \mathrm{ml}$ $\mathrm{H}_{2} \mathrm{SO}_{4}$ pekat), untuk parameter COD, TOC, Fosfat, ammonia, dll.

c. Pengawetan dengan penambahan $\mathrm{HNO}_{3}$ pekat sampai $\mathrm{pH}<2$ dan pendinginan $4^{\circ} \mathrm{C}$. (Untuk 1 liter contoh air ditambah $\pm 1 \mathrm{ml}$ $\mathrm{HNO}_{3}$ pekat) untuk parameter logam berat, kesadahan, dll.

d. Pengawet dengan penambahan $\mathrm{NaOH}$ sampai pH 12 untuk parameter $\mathrm{H}_{2} \mathrm{~S}$ dan $\mathrm{CN}$.

\subsection{Baku Mutu Air Limbah}

Baku mutu air limbah diatur dalam Keputusan Menteri Negara Lingkungan Hidup Nomor 113 Tahun 2003 Tentang Baku Mutu Air Limbah Bagi Usaha dan atau Kegiatan Pertambangan Batubara (Linggasari, 2018). Baku mutu air limbah kegiatan penambangan batubara dengan parameter satuan kadar maksimum yaitu sebagai berikut

1. $\mathrm{pH}$ 6-9,

2. Residu Tersuspensi $400 \mathrm{mg} / \mathrm{l}$,

3. Besi (Fe) Total $7 \mathrm{mg} / \mathrm{l}$, dan

4. Mangan (Mn) Total $4 \mathrm{mg} / \mathrm{l}$.

\section{METODOLOGI PENELITIAN}

\subsection{Jenis Penelitian}

Jenis penelitian yang akan dilakukan peneliti ialah jenis penelitian yang tergolong ke dalam jenis penelitian eksperimental.

\subsection{Waktu dan Tempat Penelitian}

Pengambilan sampel di salah satu Perusahaan Tambang Batubara di Lahat. Pengujian dan analisis sampel dilakukan di Laboratorium Politeknik Akamigas Palembang. Mulai dari pengambilan sampel air limbah hasil penambangan batubara sampai pengujian dan analisis air limbah tersebut dilakukan pada bulan Februari s.d. September 2020 .

\subsection{Metode Penelitian}

Dalam penelitian ini dilakukan penggabungan antara analisis sampel dengan skala laboratorium dan pengambilan data-data di lapangan:

1. Studi literatur

Studi literatur dilakukan dengan cara pengumpulan sumber informasi yang berasal dari berbagai referensi dan data perusahaan yang berkaitan dengan tujuan penelitian, hal ini dilakukan selama penelitian berlangsung.

2. Observasi lapangan

Observasi lapangan dilakukan untuk mengamati kondisi aktual di lapangan dan mencari data-data yang diperlukan dan berhubungan dengan permasalahan yang akan dibahas pada penelitian ini.

3. Pengambilan data

Mencatat dan mengumpulkan data yang diperoleh dari pengamatan secara langsung di lapangan (data primer) dan data dari perusahaan (data sekunder)

a. Data primer

Data primer adalah data yang diperoleh dari pengamatan secara langsung di lapangan, diantaranya sebagai berikut:

1. Sampel inlet settling pond

2. Data $\mathrm{pH}$ hasil uji sampel laboratorium

3. Dokumentasi pengambilan sampel lapangan dan pengujian laboratorium

b. Data sekunder 
Data sekunder adalah data yang diperoleh dari literatur. Pengambilan data pada penelitian ini dilakukan dengan dua tahapan antara lain sebagai berikut:

a). Pengambilan data lapangan

Yaitu mengambil air asam tambang di inlet settling pond, selanjutnya melakukan pengecekan pada $\mathrm{pH}$ awal air asam tambang tersebut untuk selanjutnya dijadikan sebagai sampel uji dalam skala laboratorium.

b). Pengujian laboratorium

Yaitu pengujian yang dilakukan dengan cara mengambil 30 sampel air asam tambang yang berasal dari inlet settling pond, kemudiam air tersebut diuji dengan menggunakan skala laboratorium dimana 1 liter air dicampur dengan bahan penetral (kapur tohor dan soda ash) sebesar 0,1 gram dan 0,2 gram, dan 0,3 gram kemudian dari proses pencampuran itu diperoleh dosis yang tepat untuk menetralkan $\mathrm{pH}$ air asam tambang tersebut sehingga dapat mencapai standar baku mutu air limbah yang telah ditentukan.

4. Pengolahan data

Pengolahan data dilakukan dengan cara menggabungkan antara data primer dan data sekunder yang telah didapat sebelumnya dan menganalisis data yang diperoleh dari hasil pengujian sampel dengan menggunakan skala laboratorium yang telah dilakukan agar dapat menjawab tujuan dari pembuatan penelitian ini. Pengolahan data yang dilakukan adalah sebagai berikut:

1. Penentuan penggunaan dosis kapur tohor dan soda ash pada sampel di laboratorium.

2. Penentuan kenaikan $\mathrm{pH}$ rata-rata untuk masing-masing dosis dari kapur tohor dan soda $a s h$.

5. Hasil dan pembahasan

Setelah dilakukan pengolahan data selanjutnya dilakukan analisis dari data yang sudah diolah sebelumnya, dimana data-data tersebut dikaji dengan tujuan dari pembuatan penelitian ini.
6. Kesimpulan

Dari hasil pembahasan kemudian diambil kesimpulan untuk merangkum semua data yang berkaitan dengan penelitian ini lalu memberikan rekomendasi atau saran yang mendasar kepada perusahaan untuk penanganan air asam tambang agar dapat dilakukan secara tepat dan sesuai dengan baku mutu air limbah yang telah ditetapkan pada Keputusan Menteri Negara lingkungan Hidup Nomor 113 Tahun 2003 Tentang Baku Mutu Air Limbah Bagi Usaha dan atau Kegiatan Pertambangan Batubara.

\section{HASIL DAN PEMBAHASAN}

4.1 Hasil

Hasil penelitian yang dilakukan dapat terlihat seperti pada gambar berikut ini.

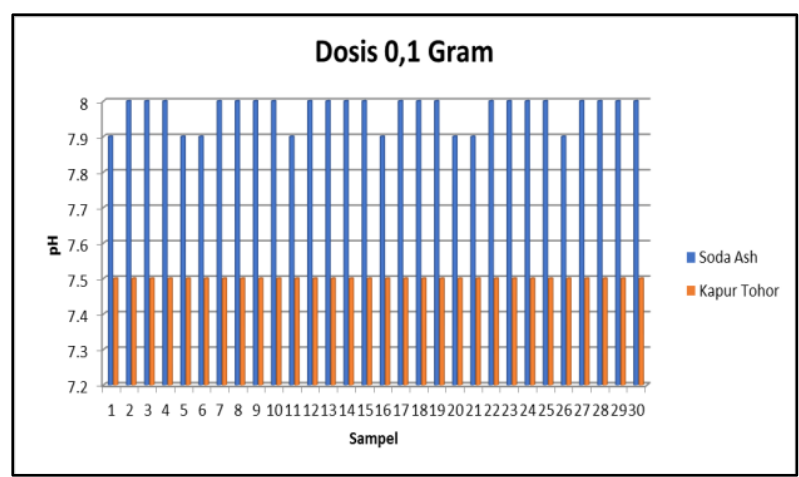

Gambar 4.1 Grafik Pengujian pH dengan dosis 0,1 gram

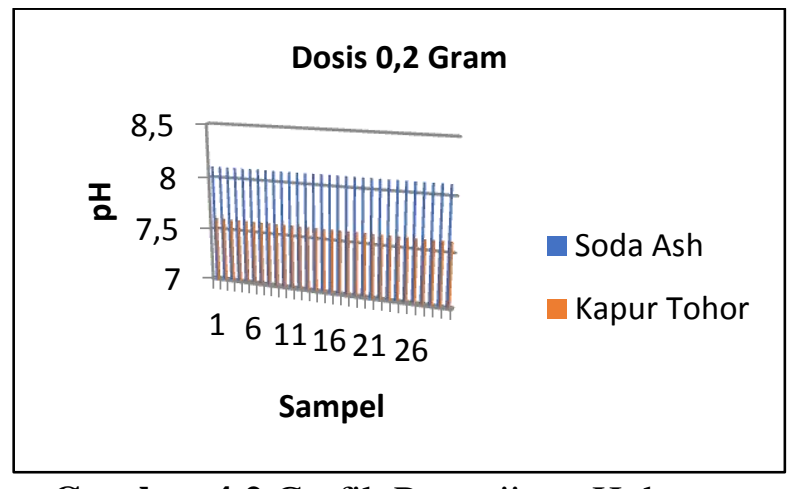

Gambar 4.2 Grafik Pengujian $\mathrm{pH}$ dengan dosis 0,2 gram 


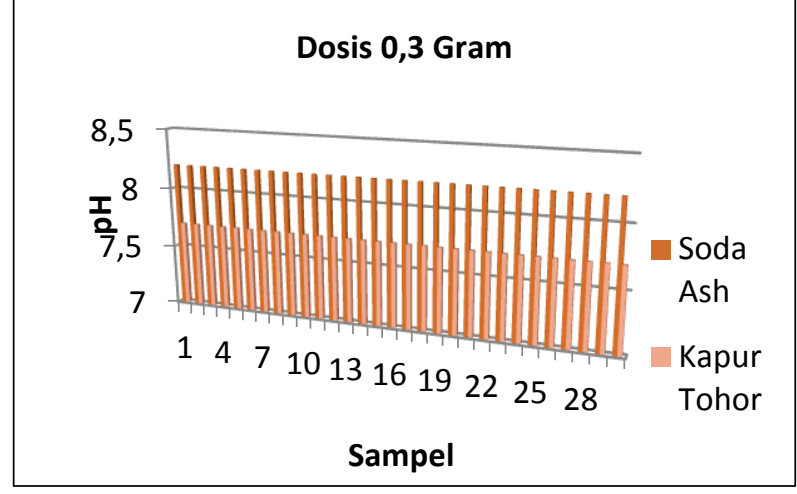

Gambar 4.3 Grafik Pengujian $\mathrm{pH}$ dengan dosis 0,3 gram

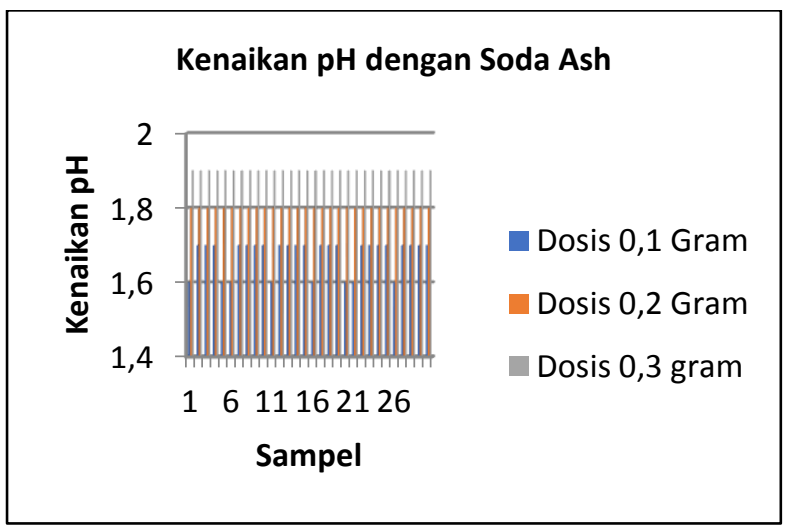

Gambar 4.4 Grafik kenaikan $\mathrm{pH}$ dengan Menggunakan Soda Ash

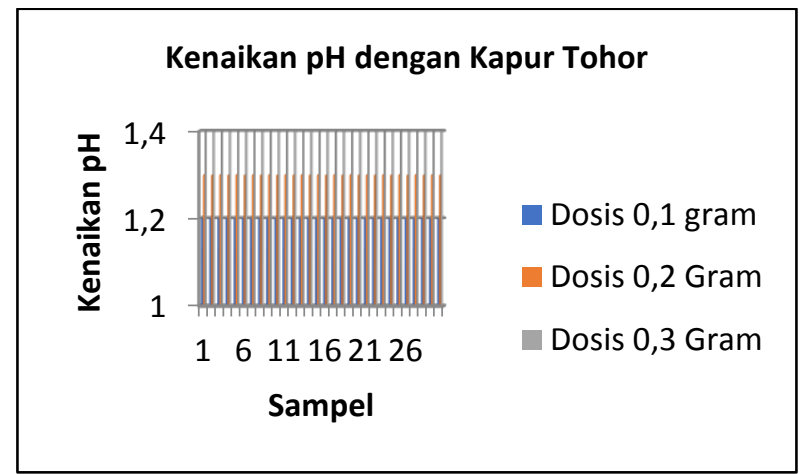

Gambar 4.5 Grafik kenaikan pH dengan menggunakan Kapur Tohor

\subsection{Pembahasan}

$\mathrm{pH}$ awal yang didapatkan di lapangan sebesar 6,3 sudah memenuhi baku mutu lingkungan. Pada penelitian ini lebih difokuskan pada perbandingan kenaikan $\mathrm{pH}$ dengan menggunakan soda ash dan kapur tohor. Dari hasil pengujian di laboratorium didapatkan untuk soda ash pada dosis 0,1 gram kenaikan $\mathrm{pH}$ rata-rata sebesar 1,673; pada dosis 0,2 gram kenaikan $\mathrm{pH}$ rata-rata sebesar 1,8 ; dan pada dosis 0,3 gram kenaikan $\mathrm{pH}$ ratarata sebesar 1,9. Hasil pengujian di laboratorium didapatkan untuk kapur tohor pada dosis 0,1 gram kenaikan $\mathrm{pH}$ rata-rata sebesar 1,2; pada dosis 0,2 gram kenaikan $\mathrm{pH}$ rata-rata 1,3; dan pada dosis 0,3 gram kenaikan $\mathrm{pH}$ rata-rata sebesar 1,4.

Berdasarkan hasil pengujian tersebut didapatkan tingkat keefektifan kenaikan $\mathrm{pH}$ menggunakan soda ash lebih tinggi daripada kapur tohor, hal ini juga dapat dipertegas dengan teori yang menyatakan bahwa sifat soda ash lebih cepat larut dibandingkan kapur tohor. Oleh karena itu, dalam penelitian ini dapat disimpulkan bahwa berdasarkan kenaikan $\mathrm{pH}$, bahan penetral soda ash lebih efektif dibandingkan kapur tohor.

\section{KESIMPULAN DAN SARAN}

\subsection{Kesimpulan}

Berdasarkan hasil dan pembahasan didapatkan kesimpulan dalam penelitian ini adalah bahan penetral soda ash lebih efektif dalam meningkatkan $\mathrm{pH}$ dibandingkan dengan kapur tohor.

\subsection{Saran}

Untuk memperbaiki hasil dan pengembangan penelitian ini, maka disarankan dalam penelitian selanjutnya dapat diteliti lebih dalam mengenai indikator lain bukan hanya tingkat kenaikan $\mathrm{pH}$ misalnya secara ekonomis dan teknis yang lainnya.

\section{DAFTAR PUSTAKA}

Anonim. 2014. Baku Mutu Air Limbah bagi Usaha Pertambangan Batubara (Keputusan Menteri Lingkungan Hidup nomor 113 tahun 2003).

Anonim. 2014. Metode Sampling. Laboratorium Lingkungan TL-3103. Bandung: ITB.

Fitri, Annisa. 2019. Perbandingan Efektivitas Penetralan Air Asam Tambang antara Kapur 
Tohor dan Soda Ash pada Tambang Batubara. Tugas Akhir Politeknik Akamigas. Palembang

Linggasari, Shenny, et.al. 2018. Perhitungan Soda Ash untuk Menetralkan Air Asam Tambang pada Penambangan Bijih Timah di Area Nibung PT Kobatin, Provinsi Bangka Belitung. Yogyakarta: UPN Veteran.

Metboki, Matilda. et.al. 2018. Analisis Masa Pakai Kapur Tohor $\left(\mathrm{CaCO}_{3}\right)$ dan Zeolit Alam Sebagai Bahan Penetral Air Asam dan Penyerap Kadar Logam Fe pada Kolam Pengendapan (Settling Pond) PT SAG KSO PT Semen Kupang. Yogyakarta: UPN Veteran. 